\title{
Farklı Ultrasonik Ses Dalgası Uygulamalarının Solanum torvum Tohumlarındaki Çimlenme ve Çıkıș Değerleri Üzerine Etkisi
}

\author{
Murat DEMIRSOY ${ }^{1 *}$, Metin AYDIN ${ }^{2}$, Burak GÜRBÜZ ${ }^{3}$ \\ Geliş / Received: 02/04/2020 \\ Revize / Revised: 09/06/2020 \\ Kabul / Accepted: 09/06/2020
}

\section{$\overline{\mathbf{O Z Z}}$}

Bu çalışma, farklı ultrasonik ses dalgası uygulamalarının Solanum torvum tohumlarındaki çimlenme ve çıkış değerleri üzerine etkisini tespit etmek amacı ile yürütülmüştür. Bu amaçla tohumlar ultrasonik ses dalgası cihazı aracılığı ile 2 ultrasonik ses dalgası şiddeti (50\% ve 100\% amplitude) ve 3 ultrasonik ses dalgası süresi $(5,10$ ve $15 \mathrm{dk})$ uygulamasına maruz bırakılmıştır. Bu uygulamaların Solanum torvum tohumlarının çimlenme oranı (\%), ortalama çimlenme süresi (OÇS), çimlenme indeksi, çimlenme hızı G50 (gün), çıkış oranı (\%), ortalama çıkış zamanı (OÇZ), çıkış indeksi ve çıkış hızı E50 (gün) üzerine etkileri ortaya konulmuştur. Araştırma sonucunda, tüm çimlenme ve çıkış değerleri açısından genel olarak 5A5D (50 amplitude-5 dakika) uygulamasının kontrole göre oldukça iyi sonuçlar verdiği tespit edilmiştir. Kontrol uygulamasında $60 \%$ civarında olan çimlenme ve çıkış oranları 5A5D uygulamasında sırası ile 96\% ve 90\% olarak belirlenmiştir. Ancak ortalama çimlenme süresi ve çıkış süresi açısından istatistiki olarak öne çıkan uygulama bulunmamıştır. Çimlenme hızı G50 ve çıkış hızı E50 değerleri yönünden 5A5D uygulamasının 4 gün kadar erken çimlenme ve çıkış sağladığı tespit edilmiştir. Ayrıca 5A5D ultrasonik ses dalgası uygulamasının, erken çimlenme ve yüksek oranda çimlenme ve çıkış oranları üzerine olumlu etkilerinin olduğu belirlenmiştir. Elde edilen sonuçların tohum çimlenme ve çıkış oranı açısından sorun yaşanan birçok bitki türünde kullanımlarına yönelik çalışmalar yapılması planlanmaktadır. 


\title{
Effects on Germination and Emergence Performance of the Solanum torvum Seeds of Different Ultrasound Treatment
}

\begin{abstract}
The study was conducted to examine the effects of different ultrasound treatment on seed germination and seedling emergence of the Solanum torvum seeds. In study, 2 different ultrasonic sound wave strength (50\% and $100 \%$ amplitude) and 3 different ultrasonic sound wave duration (5,10 and $15 \mathrm{~min}$ ) were applied by ultrasonic sound wave device. Effects on germination rate (\%), average germination time (AGT), germination index, germination rate G50 (day), seedling emergence rate (\%), average seedling emergence time (ASET), seedling emergence index and seedling emergence rate E50 (day) values of ultrasonic sound wave strength and ultrasonic sound wave duration on Solanum torvum seeds were demonstrated. In terms of all these seed germination and seedling emergence values, the application of 5A5D (50 amplitude-5 minute) gave good results compared to the control. The seed germination and seedling emergence rate were determined as $60 \%$ in the control application and as $96 \%$ and $90 \%$ in 5A5D application respectively. No statistically significant application was observed in terms of average seed germination time and seedling emergence time. 5A5D application was determined to cause earlier germination about 4 days in terms of germination rate E50 and G50. It has been determined that 5A5D ultrasonic sound wave application has very positive effects on early and high germination and seedling emergence. This study showed that ultrasonic sound wave method can be tried in many plants that have problems in terms of seed germination and emergence rate.
\end{abstract}

Keywords- Solanum torvum,Ultrasound, Germination, Emergence, Seedling. 


\section{GİRIŞ}

Ticari fide üretiminin gün geçtikçe arttığı ülkemizde, 2017 verilerine göre 148 adetin üzerinde hazır fide üretim tesisinde yıllık yaklaşık 2.91 milyar adet hazır fide üretimi gerçekleştirilmektedir. Bu değer türler bazında incelendiğinde yıllık olarak 1.07 milyar adet fide üretimi ile domates ilk sırada yer almaktadır. Patlıcan fidesi ise 61.2 milyon adet üretilmektedir [1]. Türkiye'de aşılı fide üretiminde de gün geçtikçe üretim artışı görülmektedir. Aşılı fide üretimi için patlıcanda birçok farklı anaç kullanılmaktadır. Patlıcan ve domatesin ticari hazır fide üretiminde en çok Solanum torvum anacı kullanılmaktadır [2]. Bu anaç Fusarium solgunluğuna (Fusarium oxysporum f. sp. melongenae) karşı da dayanıklıdır. Bu virüs enfeksiyonlarının azaltılması yönünden de tercih edilmektedir. Ayrıca bu anaç bitkide toplam verim artışı sağlamaktadır. Yüksek aşı tutma oranı ve birçok toprak patojenine karşı dirençli olması sayesinde Solanum torvum oldukça popülerdir [3].

Bitkisel üretimde, başarının ilk koşulu yeterli ve sağlıklı çimlenmedir. Ancak çimlenme döneminde bitki yetiştiriciliğini sınırlandıran pek çok biotik ve abiotik stres unsuru oluşabilmektedir. Başarılı bir yetiştiricilik için bu problemlerden sakınmanın agronomik, teknik veya genetik yollarının araştırılması gerekmektedir. Patlıcan ve domates yetiştiriciliğinde anaç olarak kullanılan Solanum torvum toprak kökenli pek çok biotik (Verticillium dahliae ve Fusarium oxysporum vs.) ve abiyotik (düşük toprak sıcaklığı vs.) stres unsurlarına yeterli dayanıma sahiptir. Ancak Solanum torvum tohumlarının çimlenme oranı ve kalitesinde yetersizlikler mevcuttur [4].

Bitkisel üretimde birçok türde çıkış oranı ve çıkış hızı gibi tohumların ekim öncesi performanslarının artırılmasına yönelik olarak birçok çalışma yapılmıştır [4-6]. Bu amaç doğrultusunda fiziksel (1slatma, soğuklama, sıcak uygulaması, 1şık, manyetik alan vb.) ve kimyasal (asidik veya bazik kimyasallar, bitki büyüme düzenleyicileri vb.) birçok farklı yöntem kullanılmıştır. Yapılan literatür taramaları sonucu bazı kimyasal yöntemlerle tohumların çimlenme oranının belirli miktarda arttırıldığı görülmüştür [6-8]. Tohumlarda çimlenmenin iyileştirilmesi ve dormansinin ortadan kaldırılması için yapılan uygulamalardan birisi de ultrasonik ses dalgası uygulamalarıdır. Farklı tohumlarda yapılan çalışmalar sonucunda ultrasonik ses dalgası uygulamalarının çimlenme ve çıkış hızında artış gösterdiği bildirilmiştir [5, 6, 9]. Bu çalışmalara benzer olarak birçok farklı türde yapılan araştırmalarda ultrasonik ses dalgasının çimlenme oranını olumlu yönde etkilediği Tablo 1'de ortaya konulmuştur [10].

Tablo 1. Farklı türlerin tohum çimlenme oranı üzerine ultrasonik ses dalgalarının etkisi [10].

\begin{tabular}{lccc}
\hline Çalışma Kaynağı & Tür & Çimlenme Oranı (\%) \\
\hline & & Kontrol & Ultrasonik Ses Dalgası \\
\hline$[11]$ & Calanthe discolor & 10 & $60^{*}$ \\
{$[12]$} & Hordeum vulgare L. & 93 & $99^{*}$ \\
{$[13]$} & Cicer arietinum & 61 & $97^{*}$ \\
{$[13]$} & Triticum aestivum & 98 & $100^{*}$ \\
{$[13]$} & Citrullus vulgaris & 98 & $100^{*}$ \\
{$[14]$} & Triticum aestivum & 90 & $94^{*}$ \\
{$[14]$} & Lens culinaris, Med. & 92 & $98^{*}$ \\
{$[15]$} & Lotus corniculatus L. & 77.1 & $86.1^{*}$ \\
{$[16]$} & Panicum virgatum L. & 66.9 & $90.1^{*}$ \\
{$[17]$} & Foeniculum vulgare & 90 & $59.5^{*}$ \\
{$[18]$} & Helianthus annuus L. & 54.6 & $98^{*}$ \\
{$[18]$} & Picea abies (L.) Karsten & 46 & $68^{*}$ \\
{$[19]$} & Pisum Sativum & 85 & $98.1^{*}$ \\
{$[20]$} & Medicago scutellata (L.) Mill & 33.3 & $96.6^{*}$ \\
{$[21]$} & Atriplex lentiformis & 40 & $68^{*}$
\end{tabular}




\begin{tabular}{cccc}
\hline$[21]$ & Zygophyllum eurypterum & 37.5 & $73.3^{*}$ \\
{$[22]$} & Festuca arundinacea & 38.7 & $78.7 *$ \\
{$[22]$} & Psathyrostaehys juncea Nevski & 39.3 & $89.3 *$ \\
\hline
\end{tabular}

*Yapılmış çalışmaların sonuçlar istatistiksel anlamda önemli bulunmuştur.

Çalışmada gün geçtikçe önemli bir ekonomik değer haline gelen aşılı fide üretiminde anaç olarak kullanılan Solanum torvum tohumlarındaki düşük çimlenme ve çıkış değerlerinin artırma olanakları araştırılmıştır.

\section{MATERYAL VE METOT}

Çalışma S.Ü. Sarayönü Meslek Yüksekokulu bitki laboratuvarında 2017 yılında yürütülmüştür. Bitkisel materyal olarak mükemmel "anaç-kalem" uyumu, güçlü kök yapısı, erkenci ve yüksek verimliliği, çok iyi meyve tutumu ve nematoda karşı yüksek dayanımı sebebi ile öne çıkan Hawk çeşidi kullanılmıştır. Solanum torvum patlıcan anacı (Hawk) tohumlarının içinden kırık, ezik, zedelenmiş veya ait olduğu bitki tohumu özelliklerini göstermeyeler ayrılmıştır. Tohumlara Q700 sonicator $(20 \mathrm{khz})$ ultrasonik ses dalgası cihazı aracılığ ile 2 ultrasonik ses dalgası şiddeti (50\% ve 100\% amplitude), 3 ultrasonik ses dalgası süresi (5, 10 ve $15 \mathrm{dk})$ ve kontrol uygulaması 5 tekerrürlü olmak üzere uygulanmıştır. Çalışmamızda (her tekerrür için 20 adet tohum) toplamda kontrol dahil 700 adet Solanum torvum tohumu ve 35 adet petri kabı kullanılmıştır. Tohumlara uygulama ultrasonik su banyosu içerisinde saf su ile yapılmış ve kontrol uygulamasında da aynı süre suda bekletme işlemi yapılmıştır. Deneme uygulamalarının kısaltmaları Tablo 2'de verilmiştir.

Tablo 2. Denemede kullanılan uygulamaların kısaltmaları.

\begin{tabular}{ccc}
\hline Amplitude & Süre (dk) & Kisaltma \\
\hline $50 \%$ & 5 & $5 \mathrm{~A} 5 \mathrm{D}$ \\
$50 \%$ & 10 & $5 \mathrm{~A} 10 \mathrm{D}$ \\
$50 \%$ & 15 & $5 \mathrm{~A} 15 \mathrm{D}$ \\
$100 \%$ & 5 & $10 \mathrm{~A} 5 \mathrm{D}$ \\
$100 \%$ & 10 & $10 \mathrm{~A} 10 \mathrm{D}$ \\
$100 \%$ & 15 & $10 \mathrm{~A} 15 \mathrm{D}$ \\
Kontrol & 0 & KT \\
\hline
\end{tabular}

$\mathrm{Bu}$ çalışma faktöriyel düzende tesadüf parselleri deneme desenine göre düzenlenmiştir. Tohumlar iklimlendirme dolabında (Nüve İD 501) ISTA kuralları [23] dikkate alınarak çimlendirilmiş ve 15 gün boyunca ölçüm alınmıştır [4]. Çimlenme testinde ilk sayım 15.06.2017 tarihinde ve son sayım 30.06.2017 tarihinde yapılmıştır. Çimlendirme ortamında kullanılan kurutma kâğıtları gözenekli, çim köklerinin kâğıt içinde gelişmesini önleyecek kadar ince yapılı olarak belirlenmiştir. Çimlenme denemeleri için en uygun sıcaklık kabul edilen $25 \pm 1{ }^{\circ} \mathrm{C}$ 'de uygulanmış ve 9 cm'lik steril petri kaplarına 20'şer adet tohum yerleştirilmiştir. Tohumlar petri kaplarına yerleştirildikten sonra $10 \mathrm{ml}$ saf su ile nemlendirilmiştir. Hazırlanan petri kapları karanlık çimlenme koşullarının sağlandığı 3 kat raftan oluşan karanlık iklimlendirme dolabına konulmuştur. Çalışmamızda uygulamalar sonucunda $4,6,8,11,13$ ve 15 . günlerde sayım ve gözlemler aynı saatte yapılmıştır. Tohumlardaki kökçük uzunluğu $1 \mathrm{~mm}$ veya daha büyük olduğunda çimlenmiş sayılmıştır [4].

Yapılan çimlenme testlerinden elde edilen veriler ile çimlenme oranı, ortalama çimlenme süresi, çimlenme indeksi ve çimlenme hızı (G50) değerleri hesaplanmıştır. Çimlenme oranı; [Çimlenen tohum sayısı/Toplam tohum sayısı] x100 formülü yardımı ile yüzde olarak tespit edilmiştir [24]. Ortalama çimlenme süresi çimlenme testi başlangıcından itibaren geçen gün sayısının, bu sürede çimlenen tohum sayısına bölümüyle hesaplanmıştır [25]. 


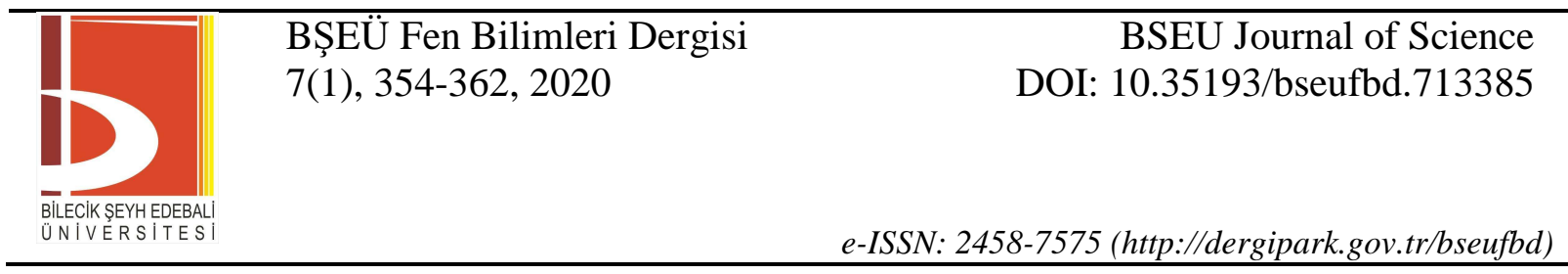

$\mathrm{OÇS}=\Sigma \mathrm{Dn} / \Sigma \mathrm{n}$

OÇS: Ortalama çimlenme suresi (gün)

D: Deneme başlangıcından itibaren sayılan günler

n: D gününde çimlenen tohum sayısı

Çimlenme hızı G50 çimlenen tohum sayısının 50\%'sinin gerçekleştiği gün olarak tespit edilmiştir. Çimlenme hızı belirli orandaki tohumun çimlenmesi için geçen zamanı ifade eder. Farklı ultrasonik ses dalgası uygulamalarına maruz bırakılmış Solanum torvum tohumlarının çimlenme verileri (çimlenen tohum sayısı/gün) esas alınarak çimlenme hızları hesaplanmıştır. Çimlenme indeksi, günde çimlenen tohum sayısının çimlenme testi başlangıcından itibaren geçen gün sayısına bölünmesi ile hesaplanmıştır [26].

Çimlenme indeksi $=\Sigma \mathrm{G} / \mathrm{D}=(\mathrm{G} 1 / \mathrm{D} 1)+(\mathrm{G} 2 / \mathrm{D} 2)+(\mathrm{G} 3 / \mathrm{D} 3)+\ldots .+(\mathrm{GL} / \mathrm{DL})$

G1: ilk kayıtta çimlenen tohum sayısı

GL: son kayıtta çimlenen tohum sayısı

D1: ilk kayıtta gün sayısı

DL: son kayıtta gün sayısı

Çıkış değerlerinin tespiti için her uygulama tekerrüründen 24 adet olmak üzere toplamda kontrol dahil 840 adet tohum ekimi ( $1 \mathrm{~cm}$ derinliğe) yapılmıştır. Tohumların çıkış özelliklerinin tespit edilebilmesi için farklı ultrasonik ses dalgası uygulamalarına maruz bırakılmış Solanum torvum tohumları 3 birim torf ve 1 birim tarım perliti karışımı ile doldurulmuş 24 hücreli viyollere ekilmiştir. Her bir viyol gözüne tek bir tohum gelecek şekilde ekimleri yapılmıştır. Fidelerin kotiledon yaprakları yere paralel olduğu zaman çıkış kriteri olarak kabul edilmiş ve 20 gün süreyle sayımlara devam edilmiştir [27, 28]. Çıkış testinde ilk sayım 15.06.2017 tarihinde ve son sayım 05.07.2017 tarihinde yapılmıştır. Çıkış oranı belli bir zaman diliminde toprak yüzeyine çıkan bitki sayısı olarak değerlendirilmiş, [Çıkan fide sayısı / Toplam ekilen tohum sayısı] x100 formülü yardımı ile yüzde olarak tespit edilmiştir. Ortalama çıkış süresi çıkış testi başlangıcından itibaren geçen gün sayısının, bu sürede çıkış gösteren tohum sayısına bölümüyle hesaplanmıştır. Çıkış indeksi günde çıkış gösteren tohum sayısının çıkış testi başlangıcından itibaren geçen gün sayısına bölünmesi ile hesaplanmıştır [25]. Çıkış hızı (E50) çıkış gösteren tohum sayısının 50\%'sinin gerçekleştiği gün olarak tespit edilmiştir. Çıkış hızı, farklı ultrasonik ses dalgası uygulaması görmüş Solanum torvum tohumlarının çıkış sayısının güne bölünmesi esas alınarak tespit edilmiştir. Elde edilen verilerin istatistiksel karşılaştırmaları One-Way Anova ve Duncan testi yöntemiyle $\mathrm{P}<0.05$ ve $\mathrm{P}<0.01$ düzeyinde yapılmıştır. Bu analizler için, SPSS 22 paket programı kullanılmıştır.

\section{BULGULAR VE TARTIŞMA}

Çalışmada Solanum torvum tohumlarına farklı ultrasonik ses dalgası uygulamaları sonucu yapılan çimlenme testlerinden elde edilen veriler Tablo 3'te verilmiştir.

Tablo 3. Solanum torvum tohumlarında farklı ultrasonik ses dalgası uygulamalarının çimlenme oranı (\%), ortalama çimlenme süresi (OÇS), çimlenme hızı (G50) ve çimlenme indeksi değerleri.

\begin{tabular}{cccccccc}
\hline Uygulama & 5A5D & 5A10D & 5A15D & 10A5D & 10A10D & 10A15D & KT \\
\hline Çimlenme Oranı (\%) & $96 \mathrm{a}$ & $81,78 \mathrm{ab}$ & $74,67 \mathrm{~b}$ & $48,22 \mathrm{~cd}$ & $41,33 \mathrm{~d}$ & $37,89 \mathrm{~d}$ & $59,89 \mathrm{c}$ \\
OÇS & 12,32 & 12,40 & 12,55 & 12,56 & 12,26 & 12,56 & 12,47 \\
G50 & $8,00 \mathrm{a}$ & $9,33 \mathrm{a}$ & $11,00 \mathrm{a}$ & $14,33 \mathrm{bc}$ & $15,00 \mathrm{c}$ & $15,00 \mathrm{c}$ & $11,67 \mathrm{ab}$ \\
Çimlenme İndeksi & $7,97 \mathrm{a}$ & $6,12 \mathrm{ab}$ & $5,55 \mathrm{abc}$ & $3,40 \mathrm{bc}$ & $3,41 \mathrm{bc}$ & $2,92 \mathrm{c}$ & $4,62 \mathrm{bc}$ \\
\hline
\end{tabular}

a-d: Aynı satırdaki farklı harfler istatistik bakımdan önemlidir $(\mathrm{p}<0.01)$.

Çimlenme oranı incelendiğinde 96\%'lık çimlenme oranı ile 5A5D uygulamasının istatistiki olarak önemli derecede öne çıktığı tespit edilmiştir. 50\% amplitude ultrasonik ses dalgası uygulamasının süresi uzadıkça çimlenme oranında azalma gösterse de kontrole oranla çimlenme oranının arttığı belirlenmiştir. Bu 
sonuca paralel olarak, arpa üzerinde yapılan bir çalışmada ultrasonik ses dalgası uygulamasının çimlenme oranını artırdığını bildirmişlerdir [12]. Ayrıca çalışmamızda; 100\% amplitude uygulamasının küçük boyutlu olan Solanum torvum tohumlarında fiziksel zarar verdiği gözlemlenmiş ve çimlenme oranlarında kontrole göre azalan sonuçlar elde edilmiştir [5]. Ispanak tohumlarında $40 \mathrm{kHz}$ ultrasonik su banyosu içerisinde 0, 20, 40, 60 ve $80 \mathrm{dk}$. süresince uygulama yapılan ultrasonik ses dalgası uygulamasının çimlenme ve çıkış değerlerini olumlu yönde etkilediği bildirilmiştir. Ayrıca bir ultrasonik ses dalgası uygulamasının belirli bir süreye kadar (40 dk) çimlenme ve çıkış değerlerini artırdığı, daha yüksek uygulama sürelerinde çimlenme ve çıkış değerlerinde azalma görüldüğü bildirilmiştir [9].

Deneme verileri incelendiğinde ortalama çimlenme süresi açısından uygulamalar arasında istatistiki olarak fark bulunmamış ve değerler 12.26 ile 12.56 gün arasında değişmiştir. G50 değeri açısından istatistiksel olarak 5A5D uygulamasının önemli derecede öne çıktığı tespit edilmiştir. Bu uygulamanın Solanum torvum tohumlarında kontrole göre G50 değerine yaklaşık 4 gün erkencilik sağlandığı gözlemlenmiştir. Arpa tohumunda yapılan bir çalışmada ultrasonik ses dalgasının farklı değerlerinde çimlenme süresinin (30\%-45\%) azaldı ̆̆ belirtilmiştir [12]. Ispanakta yapılan çalışmada kontrol uygulamasındaki tohum ile kıyaslandığında ultrasonik ses dalgası uygulamalarının ortalama çıkış zamanı açısından önemli ölçüde azalma olduğu tespit edilmiştir [9].

Çimlenme indeksi açısından 50\% amplitude uygulamaları öne çıkmıştır. 50\% amplitude uygulamaları içinde 5A5D uygulaması 7.97 değeri ile istatistiki olarak $\mathrm{P}<0.01$ düzeyinde önemli derecede farklı çıkmıştır. Özellikle kısa süreli ultrasonik ses dalgası uygulamalarında kontrole göre oldukça olumlu sonuçların ortaya çıktığı belirlenmiştir. Bu sonuca benzer olarak Senna multijuga tohumlarında yapılan çalışmada ultrasonik ses dalgası uygulamasının kontrole göre çimlenme indisini artırdığı bildirilmiştir [29].

Farklı ultrasonik ses dalgası uygulamaları sonucu Solanum torvum tohumlarına yapılan uygulamalardan elde edilen çıkış testi verileri Tablo 4'te verilmiştir.

Tablo 4. Solanum torvum tohumlarında farklı ultrasonik ses dalgası uygulamalarının çıkış oranı (\%), ortalama çıkış zamanı (OÇZ), çıkış hızı (E50) ve çıkış indeksi değerleri $(\mathrm{P}<0.01)$.

\begin{tabular}{cccccccc}
\hline Uygulama & 5A5D & 5A10D & 5A15D & 10A5D & 10A10D & 10A15D & KT \\
\hline Çıkış Oranı (\%) & $89,58 \mathrm{a}$ & $82,64 \mathrm{~b}$ & $78,47 \mathrm{c}$ & $63,89 \mathrm{~d}$ & $65,28 \mathrm{~d}$ & $50,69 \mathrm{f}$ & $61,11 \mathrm{e}$ \\
OÇZ & 10,19 & 10,09 & 10,44 & 10,35 & 10,77 & 10,54 & 10,26 \\
E50 & $9,57 \mathrm{a}$ & $10,33 \mathrm{a}$ & $12,66 \mathrm{~b}$ & $16,00 \mathrm{c}$ & $16,00 \mathrm{c}$ & $16,00 \mathrm{c}$ & $13,68 \mathrm{~b}$ \\
Çıkış İndeksi & $18,37 \mathrm{a}$ & $16,29 \mathrm{a}$ & $11,40 \mathrm{~b}$ & $11,16 \mathrm{~b}$ & $8,42 \mathrm{c}$ & $7,02 \mathrm{c}$ & $11,21 \mathrm{~b}$ \\
\hline
\end{tabular}

a-e: Aynı satırdaki farklı harfler istatistik bakımdan önemlidir $(\mathrm{p}<0.01)$.

Çıkış oranı grafiği incelendiğinde 89,58\%'lik oranı ile çimlenme oranında olduğu gibi 5A5D uygulamasının en yüksek çıkış oranına sahip olduğu tespit edilmiştir. Çıkış oranı değeri kontrolde $61.11 \%$ olarak belirlenirken 10A15D uygulamasında 50.69\%'a kadar düşmüştür. Arpa tohumlarında yapılan çalışmada $20 \mathrm{kHz}$ dalga boyuna sahip ultrasonik ses dalgası cihazı ile farklı ultrasonik ses dalgası uygulamalarının tohumda çıkış değerlerini yükselttiği belirtilmiştir [5]. Bu sonuç bizim çalışmamızdaki çıkış oranı verilerini destekler niteliktedir. Ortalama çıkış süresi değerleri incelendiğinde uygulamalar arasında istatistiki olarak bir fark bulunmamış ve değerler 10.09 ile 10.54 gün arasında değişmiştir Deneme verileri incelendiğinde E50 değeri açısından istatistiksel olarak 50\% amplitude uygulamasının 5 ve $10 \mathrm{dk}$ sürelerinin belirgin biçimde öne çıktığ gözlemlenmiştir. 5A5D uygulamasının Solanum torvum tohumlarında kontrole göre E50 değerine yaklaşık 4 gün erkencilik sağladığı belirlenmiştir. Çıkış indeksi açısından E50 değerinde olduğu gibi 50\% amplitude uygulamasının 5 ve $10 \mathrm{dk}$ sürelerinin istatistiki olarak $\mathrm{P}<0.01$ düzeyinde oldukça önemli bulunmuştur.

Çimlenme değerlerine paralel olarak süre ve amplitude değeri arttıkça çıkış indeksinde azalma gözlenmiştir. Ancak kısa süreli ultrasonik ses dalgası uygulamasının kontrole göre oldukça olumlu sonuçlarının ortaya çıktığı belirlenmiştir. Uygulamada amplitude değeri ile süre yükseldikçe indeks değerinde düşme gözlemlenmiştir. Ayçiçeği tohumlarında yapılan çalışmada artan ultrasonik şiddetinin tohum çıkış indeksini 
arttırdığı bildirilmiştir. Ultrasonik ses dalgası ile muamele edilen tohumların tohum çıkış indeksinin kontrol tohumlarından daha fazla olduğunu ancak uygulama süresi arttıkça azalma görüldüğünü belirtmişlerdir. En yüksek fide tohum çıkış indeksinin 10 dakikalık ultrasonik uygulamasında tespit edildiğini bildirmişlerdir [18].

\section{SONUÇ}

Araştırmamızda farklı ultrasonik ses dalgası kombinasyonları denenmiştir. Deneme sonucunda ultrasonik ses dalgası uygulamaları ile tohumun bünyesine su alımı sonucu çıkış oranını ve hızını artırmak hedeflenmiştir. Bu uygulama kombinasyonları sonucunda en yüksek homojen tohum çıkışlarına sahip kombinasyonlar belirlenmiştir. Solanum torvum tohumlarının çimlenme oranı (\%), ortalama çimlenme süresi (OÇS), çimlenme indeksi, çimlenme hızı G50 (gün), çıkış oranı (\%), ortalama çıkış zamanı (OÇZ), çıkış indeksi ve çıkış hızı E50 (gün) değerleri ortaya konulmuştur. Genel olarak çimlenme ve çıkış değerleri açısından 5A5D uygulaması kontrole göre oldukça iyi sonuçlar vermiştir. Kontrol uygulamasında \%60 civarında olan çimlenme oranı 5A5D uygulamasında \%96 olarak elde edilmiştir. Yine kontrol uygulamasında \%60 civarında olan çıkış 5A5D uygulamasında \%90 olarak tespit edilmiştir. OÇS ve OÇZ açısından istatistiki olarak öne çıkan bir uygulama gözlemlenmemiştir. G50 ve E50 verileri yönünden 5A5D uygulamasının erkencilik (yaklaşık 4 gün) ortaya koyduğu gözlemlenmiştir. 5A5D ultrasonik ses dalgası uygulamasının yüksek oranda çimlenme ve çıkışa oldukça olumlu etkilerinin olduğu da belirlenmiştir. Solanum torvum tohumlarında düşük değerde ultrasonik ses dalgası uygulaması kontrole göre oldukça olumlu sonuçlar ortaya çıkartırken, uzun süreli yüksek değerde ses dalgası uygulamasının kontrolden daha düşük çimlenme ve çıkış değerleri ortaya çıkardığı tespit edilmiştir.

Yapmış olduğumuz çalışmada bir diğer önemli hususta tohum çıkış oranı açısından sorun yaşanan birçok bitkide bu yöntemin denenebileceği gerçeğidir. Ultrasonik ses dalgası uygulamasının etkisinin tohumun büyüklüğü ve kabuk kalınlığına göre değişmesinden dolayı her tohuma uygun farklı uygulama süresi ve ultrasonik ses dalgası şiddeti değerlerinin belirlenmesi gerekmektedir. Bu şekilde çalışmada kullanılan yöntemin homojen çimlenme ve dormansi sorunu olan birçok türde alternatif bir yöntem olarak kullanılabilmesi mümkün olacaktır.

\section{TEŞEKKÜR}

Bu çalışma Selçuk Üniversitesi Bilimsel Araştırma Projeleri koordinatörlüğü tarafından 17401045 proje no’su ile desteklenmiştir. Yazarlar, her türlü katkı ve desteklerinden dolayı teşekkür eder.

\section{KAYNAKLAR}

[1] TAGEM. (2020). Tarım işletmeleri genel müdürlüğü tohumculuk sektör politika belgesi 2018-2022. http://www.tigem.gov.tr.

[2] Balkaya, A., Kandemir, D., \& Sarıbaş, Ş. (2015). Türkiye sebze fidesi üretimindeki son gelişmeler. TÜRKTOB Türkiye Tohumcular Birliği Dergisi, 13(4), 4-8.

[3] Balkaya, A. (2014). Aşılı sebze üretiminde kullanılan anaçlar. TURKTOB Türkiye Tohumcular Birliği Dergisi, 10, 6-9.

[4] Ranil, R., Niran, H., Plazas, M., Fonseka, R., Fonseka, H., Vilanova, S., Andújar, I., Gramazio, P., Fita, A., \& Prohens, J. (2015). Improving seed germination of the eggplant rootstock Solanum torvum by testing multiple factors using an orthogonal array design. Scientia Horticulturae, 193, 174-181.

[5] Miano, A., Forti, V., Abud, H., Gomes-Junior, F., Cicero, S., \& Augusto, P. (2015). Effect of ultrasound technology on barley seed germination and vigour. Seed Science and Technology, 43(2), 297-302.

[6] Rifna, E., Ramanan, K. R., \& Mahendran, R. (2019). Emerging technology applications for improving seed germination. Trends in Food Science \& Technology, 86, 95-108.

[7] Holubowicz, R., Kubisz, L., Gauza, M., Yilin, T., \& Hojan-Jezierska, D. (2014). Effect of low frequency magnetic field (LFMF) on the germination of seeds and selected useful characters of onion. Notulae 
Botanicae Horti Agrobotanici Cluj-Napoca, 42(1), 168-172.

[8] Bewley, J., Bradford, K., Hilhorst, H., \& Nonogaki, H. (2013). Seeds: physiology of development, germination and dormancy. Germany. 392., 392.

[9] Dönmez, F. (2018). Ultrasonik ses dalgası uygulamalarının ıspanak tohumlarında çimlenme ve çıkış üzerine etkileri. Yüksek Lisans Tezi, Süleyman Demirel Üniversitesi, Fen Bilimleri Enstitüsü, Bahçe Bitkileri Ana Bilim Dalı, Isparta.

[10] Nazari, M. \& Eteghadipour, M. (2017). Impacts of ultrasonic waves on seeds: a mini-review. Agric Res Tech Open Access J, 6(3), 55-59.

[11] Miyoshi, K. \& Mii, M. (1988). Ultrasonic treatment for enhancing seed germination of terrestrial orchid, Calanthe discolor, in asymbiotic culture. Scientia Horticulturae, 35(1-2), 127-130.

[12] Yaldagard, M., Mortazavi, S., \& Tabatabaie, F. (2007). The effectiveness of ultrasound treatment on the germination stimulation of barley seed and its alpha-amylase activity. Proceedings of World Academy of Science, Engineering and Technology, 34,, 154-157.

[13] Goussous, S., Samarah, N., Alqudah, A., \& Othman, M. (2010). Enhancing seed germination of four crop species using an ultrasonic technique. Experimental Agriculture, 46(2), 231-242.

[14] Aladjadjiyan, A. (2011). Ultrasonic stimulation of the development of lentils and wheat seedlings. Romanian Journal of Biophysics, 21(3), 179-188.

[15] Toth, I. (2012). The effects of ultrasound exposure on the germination capacity of birdsfoot trefoil (Lotus corniculatus L.) seeds. Roman J Biophys, 22(1), 13-20.

[16] Wang, Q., Chen, G., Yersaiyiti, H., Liu, Y., Cui, J., Wu, C., Zhang, Y., \& He, X. (2012). Modeling analysis on germination and seedling growth using ultrasound seed pretreatment in switchgrass. PloS one, 7(10), 110 .

[17] Fateh, E., Noroozi, H., Farbod, M., \& Gerami, F. (2012). Assessment of Fennel (Foeniculum vulgare) seed germination characteristics as influenced by ultrasonic waves and magnetic water. European Journal of Experimental Biology, 2(3), 662-666.

[18] Machikowa, T., Kulrattanarak, T., \& Wonprasaid, S. (2013). Effects of ultrasonic treatment on germination of synthetic sunflower seeds. Proceedings of World Academy of Science, Engineering and Technology, 73(1), 53-55.

[19] Chiu, K. Y. \& Sung, J. M. (2014). Use of ultrasonication to enhance pea seed germination and microbial quality of pea sprouts. International Journal of Food Science \& Technology, 49(7), 1699-1706.

[20] Nazari, M., Sharififar, A., \& Asghari, H. R. (2014). Medicago scutellata seed dormancy breaking by ultrasonic waves. Plant Breeding and Seed Science, 69(1), 15-24.

[21] Sharififar, A., Nazari, M., \& Asghari, H. R. (2015). Effect of ultrasonic waves on seed germination of Atriplex lentiformis, Cuminum cyminum, and Zygophyllum eurypterum. Journal of Applied Research on Medicinal and Aromatic Plants, 2(3), 102-104.

[22] Liu, J., Wang, Q., Karagić, Đ., Liu, X., Cui, J., Gui, J., Gu, M., \& Gao, W. (2016). Effects of ultrasonication on increased germination and improved seedling growth of aged grass seeds of tall fescue and Russian wildrye. Scientific Reports, 6, 1-12.

[23] ISTA. (2010). International Rules for Seed Testing. https://www.seedtest.org/en/international-rules-forseed-testing-_content---1--1083.html. 
[24] Sivritepe, H. Ö. (2011). Tohum canlılığının değerlendirilmesi. Alatarım, 10(2), 94-105.

[25] Süslüoğlu, Z. (2014). Bazı tohum ön uygulamalarının tatlı biber tohumlarının stres sıcaklıklarında çimlenme ve çıkış performansları üzerine etkileri. Yüksek Lisans Tezi, Bingöl Üniversitesi, Fen Bilimleri Enstitüsü, Bahçe Bitkileri Anabilim Dalı, Bingöl.

[26] Başay, S. \& Alpsoy, H. C. (2019). Biber (Capsicum annuum L. var. Sürmeli) tohumlarına yapılan vermikompost çayı ön uygulamasının çimlenme parametreleri ve fide kalite özelliklerine etkisi. Alatarım, 18(1), 23-29.

[27] Şehirali, S. (1997). Tohumluk ve teknolojisi. İstanbul, 422.

[28] Sarıbaş, H. Ş., Balkaya, A., Kandemir, D., \& Karaağaç, O. (2019). The Phenotypic Root Architectures and Rooting Potential of Local Eggplant Rootstocks (Solanum melongena x Solanum aethiopicum). Black Sea Journal of Agriculture, 2(3), 137-145.

[29] Venâncio, R. S. S. \& Martins, A. C. G. (2019). Overcoming dormancy of Senna multijuga seeds with an ultrasonic probe the comparison with ultrasound and sulfuric acid baths. Ciência Rural, 49(9), 1-7. 